\title{
Optimal Timing and Recycling Operation Mode for Electro-Mechanical Products Active Remanufacturing
}

\begin{abstract}
The uncertainties of remanufactured products in multi-life cycle service, such as injury and restoration process route, are comprehensively analyzed in the present study from perspectives of cost and the environment. Based on life cycle assessment method and the life cycle cost analysis, the optimal timing model of active remanufacturing for electro-mechanical products is established considering these uncertainties. In addition, regarding the active remanufacturing as its guidance, this study explores the economic efficiency and corresponding operation mode of electro-mechanical products when recycling in the optimal timing. To validate the optimal timing model for electro-mechanical products active remanufacturing, a specific type of product is taken as a case study with mathematical statistics method and Monte Carlo simulation.
\end{abstract}

Keywords: electro-mechanical products, active remanufacturing, optimal timing, reverse logistics, recycling mode

\section{Introduction}

With rapid development of manufacturing industry, China's GDP has been greatly promoted and the output value of China's manufacturing industry is more than 20 trillion CNY in 2013 and 2014. However, the quantity of scrap electro-mechanical products such as manufacturing equipment, vehicles and electrical equipment is surprisingly tremendous, and there are great secondary losses of energy and wasteful use of resources if scrap products are melted down for reuse. It is an important direction in engineering research field to avoid losses of resources. Remanufacturing, as an effective approach to build a resource-saving and environment-friendly society, can realize resource conservation and produces necessary

Manuscript received January 10, 2016; accepted May 20, 2016

Wang Gao, Tao Li (ه), Shi-tong Peng, Liang Wang, Hong-chao Zhang School of Mechanical Engineering, Dalian University of Technology, Dalian 116023, China

Email: litao@dlut.edu.cn products for the economic development (Xu, Dong, \& Shi, 2013). At present, the most frequently used remanufacturing method is based on end-of-life product resource recovery i.e. products remanufactured after it is decommissioned. Although this method can thoroughly utilize the products, it would lead to the reduction of remanufacturing yield as well as augment of economic costs and environmental impact. The reasons lie in the following aspects: serious breakage conditions of scrap products caused by long period of service and corresponding unfeasibility concerning the remanufacturing technology level, cost, environment and product service factors ( $\mathrm{Zhu}, \mathrm{Xu}, \&$ Yao, 2003). With the development of remanufacturing technology, active remanufacturing has emerged in recent years (Frank \& Yakut, 2004; Seliger, Frank, Ciupek, \& Basdere, 2004; Xu, 2007; Xu, 2010). There must be a remanufacturing time interval in the course of service when remanufacturing is the most cost-effective and environmental friendly.

Optimal timing research for active remanufacturing is one of the essential technologies to promote remanufacturing development. Bras and Hammond (1996), mainly discussed the comprehensive feasibility indexes of product remanufacturing through the evaluation of main process for remanufacturing. Liu, C., Cao, Liu, Du, and Ding (2007), analyzed the influence factors of waste electro-mechanical products remanufacturing, such as technology, cost, quality, resources, environment and others using qualitative and quantitative methods. According to Zhong, Fan, Yao, and Yang (2003), the comprehensive evaluation system of product remanufacturing was put forward based on the factors of durability, failure types, the rate of recovery value, technical stability, recyclability, remanufacturing process and others. Liu, Y., Xu, Shi, and Liu (2011), proposed the evaluation architecture for remanufacturing with consideration of dismantling qualified rate, detection reliability, product reliability, profit margins, environment yields, reused rate and reducing carbon emission in three aspects including technology, economy and environments. According to the different environmental impact due to the different remanufacturing time, Liu, Jiang, $\mathrm{Li}$, and Zhang (2014) calculated the timing point for engine remanufac- 
turing with the smallest environmental impact using life cycle assessment (LCA) method. Liu, G., Liu, T., Ke, Song, and Zhou (2013), proposed the concept of active remanufacturing and the methods of time decision-making for remanufacturing based on Game Theory and Neural Network. However, these methods failed to consider the optimal timing model for electro-mechanical products active remanufacturing from the aspects of environment and cost. To resolve this problem, an optimal timing model for electro-mechanical products active remanufacturing based on LCA and life cycle cost (LCC) is put forward in this paper. The model will discuss two aspects of environmental impact and economic costs respectively, and then realize finding the optimal timing for electromechanical products active remanufacturing. Based on the solution, a recycling operation mode based on the closedloop supply chain is also explored.

\section{Model descriptions}

\subsection{Academic thought of active remanufacturing}

Active remanufacturing engineering, directed by the theory of whole life cycle, is a series of industrial process of repairing or modifying worn products using high technology and industrial manufacture in an appropriate period. The same batch of worn products using the same design scheme can achieve a quantum leap in mechanical properties (Liu, G., Liu, T., Ke, Song, \& Zhou, 2013; Xu, 2007). There is usually "remanufacturing in advance" and "remanufacturing after excessive using" in remanufacturing process. Thus, the optimal timing decision-making method for electro-mechanical products active remanufacturing becomes more important. The failure rate of electromechanical products is changing with time, and the rate shows a bathtub distribution (Huang, 1990), as shown in Figure 1. The products experience three periods: initial malfunction period, random malfunction period and wearing malfunction period. Due to poor function in runin period of the products, the failure rate is higher and declining along with increase of products service time. The quality of products is steady with low failure rate in random

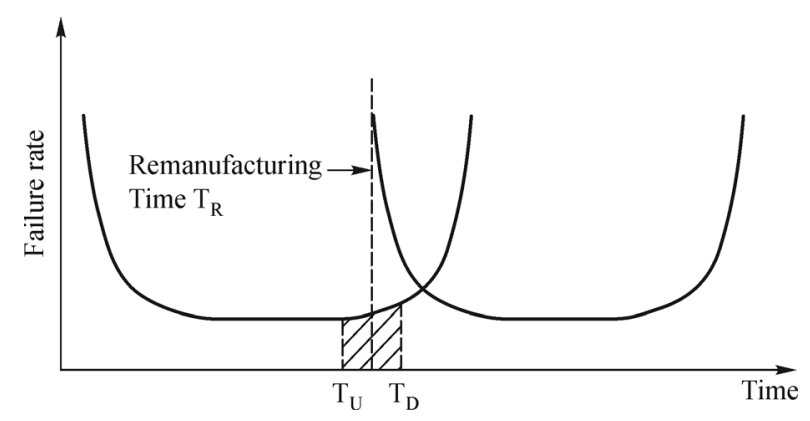

Figure 1. Failure rate of electro-mechanical products. malfunction period. With the over-long service time for products and their accelerating worn rate, they are close to be discarded with frequent failures.

Among them, $T_{U}$ is the limit of optimum performance for product remanufacturing; $T_{D}$ is the degradation threshold for product remanufacturing. The optimal timing interval for active remanufacturing is $\left[T_{U}, T_{D}\right]$. When the product remanufacturing time $T_{R}<T_{U}$, a first shorter service time of products and premature investment for remanufacturing result in remanufacturing in advance. When $T_{R}>T_{D}$, excessive wear and increasing maintenance costs lead to extreme difficulty in remanufacturing technology and growth in capital investment, which is a common phenomena of remanufacturing after excessive usage.

LCA as an important evaluation method of the whole life cycle theory has an important position in remanufacturing (Mckenna, Reith, Cail, Kessler, \& Fichtner, 2013; Zhang \& Chen, 2015). With the method of LCA, the timing for remanufacturing with the smallest environmental impact can be identified by comprehensive evaluation of materials and energy consumption and emissions of products in the process of the whole service time. Traditional evaluation does not consider the factor of economic costs. Therefore, LCC analysis need to be considered with LCA together (Hellweg \& Canals, 2014).

2.2 The uncertainty of remanufacturing factor and system boundaries

Remanufacturing processes possess more uncertainties compared with original manufacturing (Galbreth \& Blackbum, 2010; Guide, 2000; Ketzenberg, Van der Laan, \& Teunter, 2006; Teunter \& Flapper, 2010; Zikopoulos \& Tagaras, 2007). In this study, two major uncertain factors are considered: the uncertainty of service time and the degree of products damage.

Electro-mechanical products' serving time $t_{i}$ obeys normal distribution,

$$
t_{i} \sim N\left(\mu, \sigma^{2}\right)
$$

Where, $\mu$ is average service time of electro-mechanical products; $\sigma$ is the standard deviation of the distribution.

There are so many kinds of failures leading to electromechanical product's destruction, such as bending deformation, cracks, fatigue, pitting corrosion and so on, and these may exist in many forms in one product. The degree of products damage $\left[\delta_{k}\right]$ results in different kinds and dosage of repair materials and energies $X_{i}=\left[x_{k}\right] . X_{i}$ is the set of materials and energies being consumed. Equation (2) is a function of $\delta_{k}$ and $c_{k}$,

$$
c_{k}=f\left(\delta_{k}\right)
$$

Where, $c_{k}$ is the most approximate value of $x_{k}$. $x_{k}$ obeys triangular distribution, shown as Eq. (3), 


$$
\begin{aligned}
& f\left(x_{k} \mid a_{k}, b_{k}, c_{k}\right) \\
= & \begin{array}{l}
2\left(x_{k}-a_{k}\right) /\left[\left(b_{k}-a_{k}\right)\left(c_{k}-a_{k}\right)\right], a_{k} \leqslant x_{k} \leqslant c_{k} \\
2\left(b_{k}-x_{k}\right) /\left[\left(b_{k}-a_{k}\right)\left(b_{k}-c_{k}\right)\right], c_{k} \leqslant x_{k} \leqslant b_{k}
\end{array}
\end{aligned}
$$

Where, $f\left(x_{k}\right)$ is the probability density function of $x_{k} ; a_{k}, b_{k}$ and $c_{k}$ are minimum, maximum and the most approximate value of $x_{k}$ respectively.

The distributions of these situations are two kinds of value types. Moreover, the data may obey another type of distribution due to the different types of electro-mechanical products and service conditions. The model is also applicable when the data obeys another type of distribution.

This study aims to calculate the environmental emissions and economic input annual average impact curve caused by the difference of new products' service time based on the methods of LCA and LCC, and then determines the optimal timing for active remanufacturing. As shown in Figure 2, the boundaries of the system include: raw materials' mining, and a process of new electro-mechanical products including its remanufacturing, using, recovery, remanufacturing, reusing and discarding procedure.

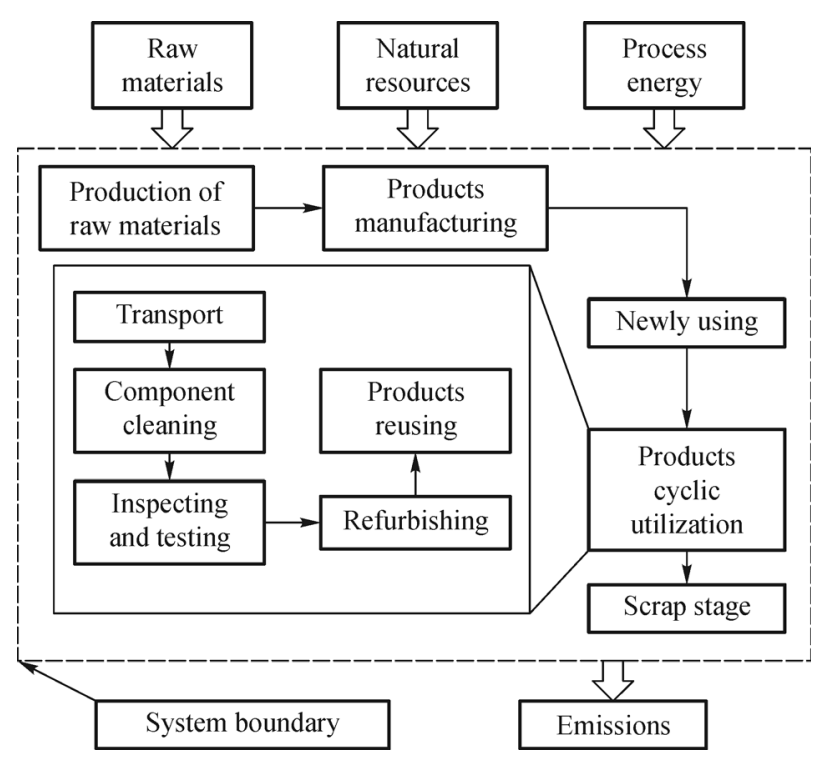

Figure 2. System boundary of electro-mechanical products active remanufacturing.

2.3 Build the optimal timing model for electro-mechanical products active remanufacturing

Aiming at economic costs and environmental impact of electro-mechanical product's life cycle, the environmental impact is converted into economic costs by "society willingness to pay" method, which would make the environmental impact fully integrated with economic costs. The model is shown in Figure 3.

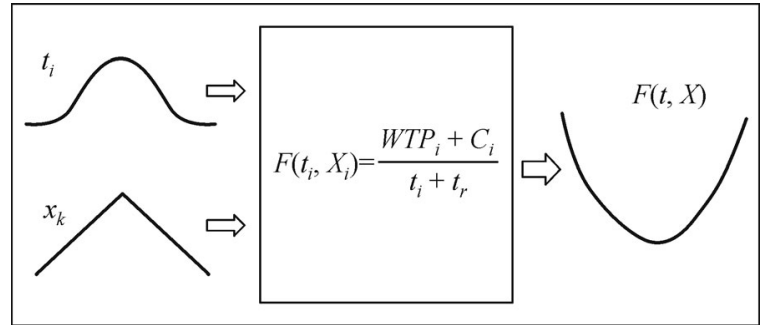

Figure 3. The optimal timing model for active remanufacturing.

The formula is as follows,

$$
F\left(t_{i}, X_{i}\right)=\frac{W T P_{i}+C_{i}}{t_{i}+t_{r}}
$$

Where, $F\left(t_{i}, X_{i}\right)$ is annual average cost of environmenteconomy of the number $i$ product; $W P T_{i}$ is the society willingness to pay for ecosystem environment degradation caused by the number $i$ product; $C_{i}$ is the economic costs of the number $i$ product's whole life cycle; $t_{i}$ is the first service time of the number $i$ product; $t_{r}$ is the service time of remanufactured product, $t_{i}$ and $t_{r}$ obey normal distribution from Eq. (1).

Since most of the initial data are random in this model, the probability distributions of the data ought to be determined. The date can be calculated with the Monte Carlo simulation method. Then, $F\left(t_{i}, X_{i}\right)$ can be calculated under uncertain conditions. When sample size is enough, curve equation can be fitted according to the least square method,

$$
y=\hat{\beta}_{1} t^{2}+\hat{\beta}_{2} t+\hat{\beta}_{3}
$$

The optimal timing with the minimum annual average cost of environment-economy can be obtained through calculating the inflection point of the curve,

$$
T_{R}=\frac{-\hat{\beta}_{2}}{2 \hat{\beta}_{1}}
$$

\subsection{Build the LCA model}

In view of the selected samples, the life cycle stage can be roughly divided into five stages: original manufacturing, use, remanufacturing, reuse and scrap process. In this study, the following assumptions are made as follows:

(1) The environmental impacts of all samples of new product manufacturing are the same;

(2) All kinds of mechanical properties of remanufactured products are consistent with new products;

(3) Remanufacturing are made in all scrap process and the environmental impacts are the same.

The listing data of substance $j$ emission of the number $i$ product throughout the life cycle can be calculated, the formula is as follows, 


$$
Q_{i j}=A_{j}+\int_{0}^{t_{i}} f(t) d t+B_{i j}+\int_{0}^{t_{r}} f(t) d t+E O L_{j}
$$

Where, $Q_{i j}$ is emission inventory data of substance $j$ in number $i$ product; $A_{j}, B_{i j}, \int_{0}^{t_{i}} f(t) d t, \int_{0}^{t_{r}} f(t) d t, E O L_{j}$ are amount of substance $j$ discharged by five stages of the number $i$ product respectively: original manufacturing, use, remanufacturing, reuse and scrap process; $t_{i}$ and $t_{r}$ are the service time (year) of the number $i$ product after original manufacturing and remanufacturing respectively.

According to the basic data of whole life cycle in the database, energy consumption, material consumption and pollution emissions of the whole life cycle can be calculated. In this study, five environmental-impact categories are assessed, including global warming potential (GWP), acidification potential (AP), eutrophication potential (EP), photochemical ozone formation potential (POCP) and primary energy demand (PED). The primary energy demand (PED) includes into coal, oil and natural gas. Then the environmental impact assessment can be analyzed according to the model of Figure 4. To ensure the superposition of environment impact and economic costs, the concept of "willingness to pay" is proposed to unify the units of environmental impact and economic costs (Herbes, Friege, Baldo, \& Mueller, 2015; Zalejska-Jonsson, 2014).

The formula of characterization is,

$$
E P_{i n}=\sum Q_{i j} \times E F_{j}
$$

Where, $E P_{i n}$ is the nth environmental impact potential of the number $i$ product; $E F_{j}$ is equivalence factor of substance $j$.

Society willingness to pay for ecosystem environment degradation caused by the number $i$ product can be obtained,

$$
W T P_{i}=\sum\left(E P_{i n} \times E C_{n}\right)
$$

Where, $E C_{n}$ is the compensation weighting factor for each per unit environmental impact potential (such as the unit of GWP is "CNY/kgeq. $\mathrm{CO}_{2}$ ").

\subsection{Build the LCC model}

The diagram of electro-mechanical product life cycle cost is as shown in Figure 5.

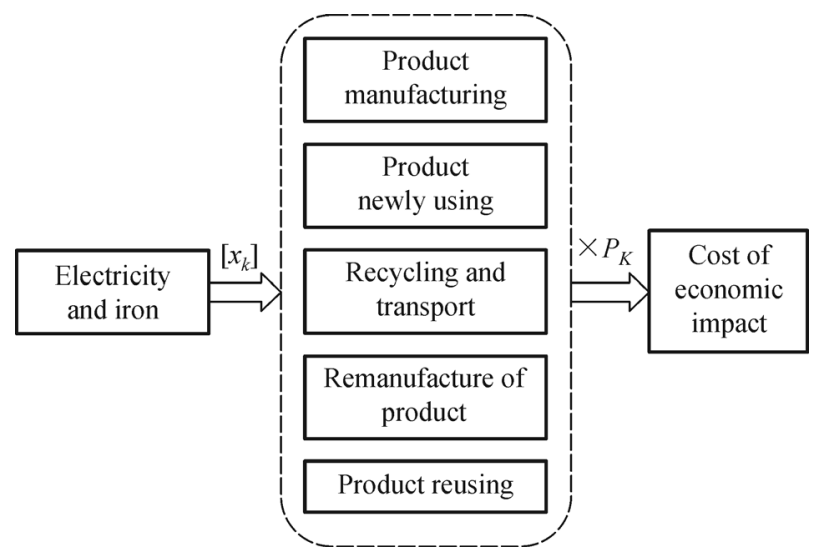

Figure 5. Diagram of product life cycle cost.

Entire costs of the number $i$ sample with the whole life cycle can be calculated, the formula is as follows,

$$
C_{i}=C_{\text {om }}+C_{\text {oui }}+C_{t}+C_{r m i}+C_{r u}+C_{\text {eol }}
$$

Where, $C_{\text {om }}, C_{\text {oui }}, C_{t}, C_{r m i}, C_{r u}, C_{\text {eol }}$ are economic costs in six stages of the number $i$ product respectively: original manufacturing, use of new components, recycling of old and discarded components, remanufacturing, reuse and scrap process. $C_{\text {oui }}$ is the function of $t_{i}$ and $C_{r u}$ is the

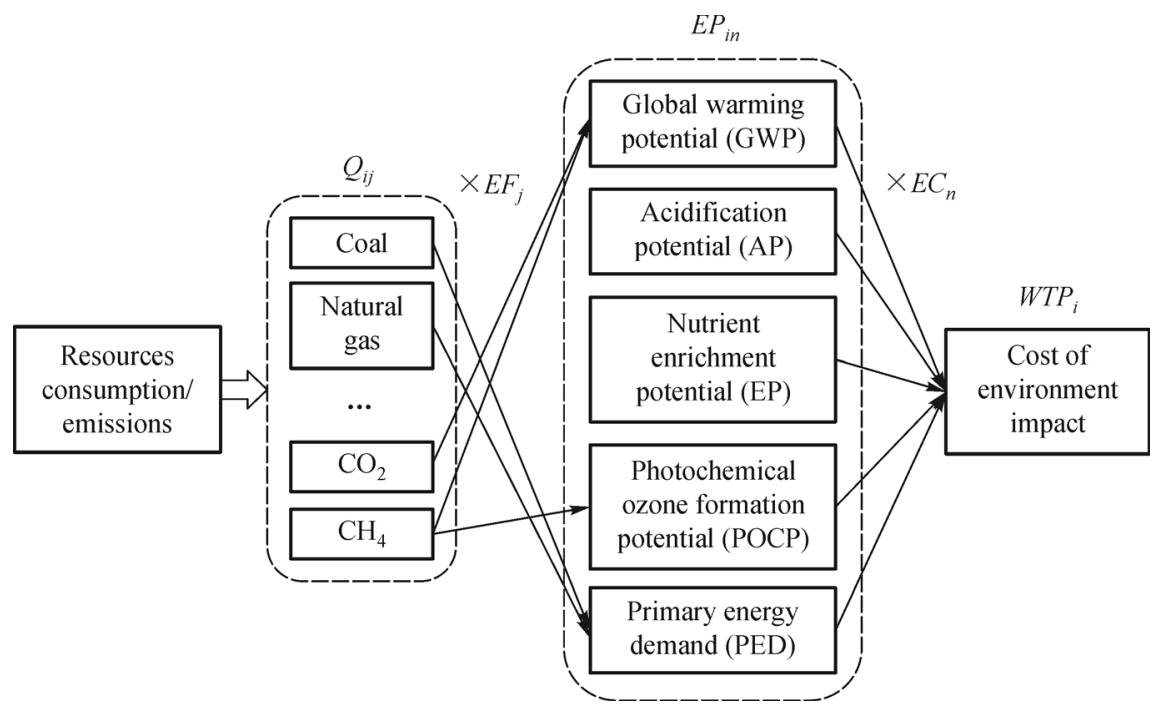

Figure 4. The model of LCA. 
function of $t_{r} . t_{i}$ and $t_{r}$ obey the normal distribution from Eq. (1).

The calculating formula of remanufacturing costs is as follow,

$$
C_{r m i}=P_{k} x_{k}+f e
$$

Where, $P_{k}$ is the price of a certain materials or energy; $x_{k}$ is the amount of a certain material or energy; $f e$ is the costs of research, management, etc.

\section{The recycling operation mode}

3.1 The necessity of a new recycling mode for electro-mechanical products

The traditional supply chain, namely forward logistics, is the process of products from manufacturers to consumers. The concept of reverse logistics was first proposed by Stock in a report submitted to US Council of Logistics Management in 1992. Reverse logistics (Stock, 1992) is a series of process of raw materials, stock and finished goods from consumption areas to the origin sites. The combination of forward logistics and reverse logistics constitutes a closed-loop supply chain of electro-mechanical products. Guide and Van Wassenhove (2002) presented a products acquisition system for enhancing the effective function of end-of-life products' recycling. Guide and Van Wassenhove (2009) focused on profitable value recovery from returned end-of-life products. And some of components can be used in new manufacturing items. Fleischmann, Beullens, Bloemh, and Van Wassenhove (2001) considered logistics network designed in a reverse logistics context and presented a generic facility location model. The analytic inventory-control model and a simulation model showed that procurement-cost savings largely outweigh reverse logistics costs in IBM (Fleischmann, Van Nunen, \& Gräve, 2003). However, these methods failed to consider the recycling mode for electro-mechanical products active remanufacturing from the aspects of the optimal timing and maintainers. And those modes did not match the products' recycling conditions in China.

In addition, compared with end-of-life remanufacturing, active remanufacturing has the obvious economic benefits. The economic benefits of active remanufacturing can be calculated through the following formula,

$$
B=\frac{1}{n} \sum_{i=1}^{n} y_{i}-y_{o p t}
$$

Where, $B$ is the economic benefits of active remanufacturing; $y_{\text {opt }}$ is the economic costs of active remanufacturing in optimal timing; $y_{i}$ is the economic costs of end-of-life remanufacturing of the number $i$ product; $n$ is the sample size.

Furthermore, the concept of "sale-buyback contract" heavily promotes the development of recycling mode for electro-mechanical products (Pasternack, 1985; Bose \& Anand, 2007). It is urgent to propose an electro-mechanical product recycling mode based on active remanufacturing.

\subsection{Build the electro-mechanical product recycling mode}

Based on these considerations, this paper proposed an electro-mechanical product recycling mode based on active remanufacturing, which is shown in Figure 6. The model includes not only manufacturers, distributors and consumers in forward logistics but also parts suppliers and maintainers.

This mode mainly involves the following characters:

(1) Original Equipment Manufacturer (OEM) of electromechanical products

OEM is the core character in this active recycling mode. OEM should not only be responsible for the key technologies and environmental protection in manufacturing process, but also have the responsibility of recycling the waste products for remanufacturing. They can use its

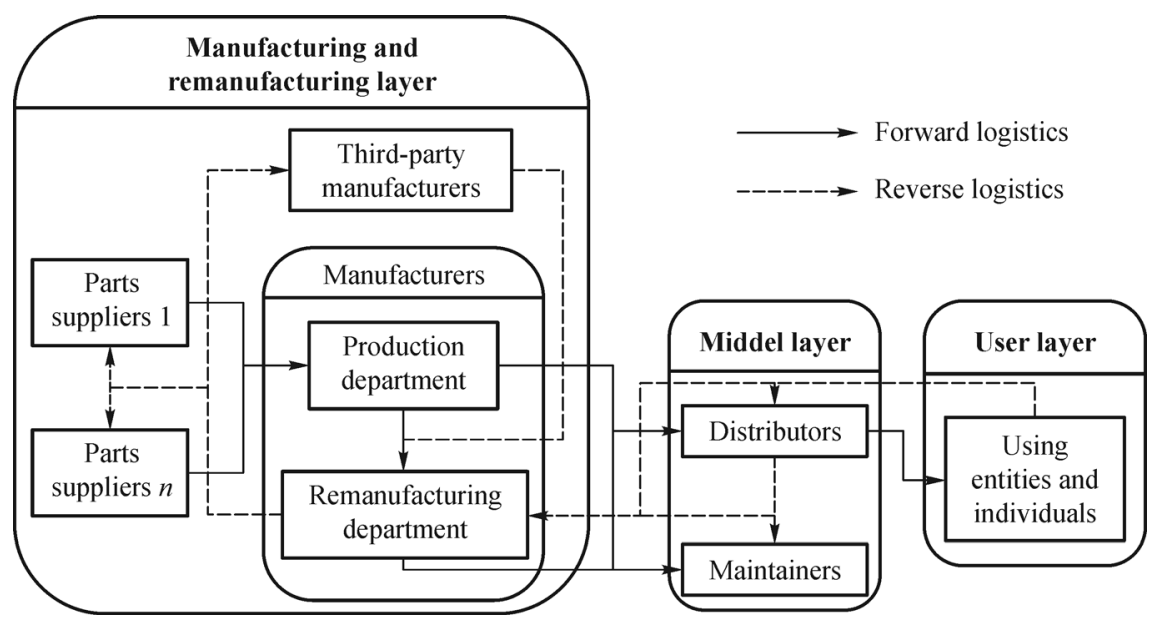

Figure 6. Recycling operation mode for electro-mechanical products. 
internal remanufacturing departments or third-party manufacturers for products' remanufacturing.

(2) Third-party manufacturers

OEM sometimes needs a third-party manufacturer to assist products' remanufacturing (Örsdemir, KemahlıogluZiyaet, \& Parlaktürkal, 2014). The technology and performance indicators of remanufactured products should be supervised by OEM.

(3) Parts suppliers

To achieve benefit maximization, OEM generally chooses several upstream parts suppliers for different parts. OEM sometimes needs to return the parts to parts suppliers for remanufacturing.

(4) Distributors of electro-mechanical products

Distributors benefit from the process of forward logistics and are big contributors to pollution. Therefore, the certain responsibility in recycle process must be undertaken. In addition, due to character properties between OEM and consumers, it is difficult and costly for communication and recycling between them. Distributors as the recycling station can obtain the optimal benefit, and it is the key role in recycling process.

(5) Maintainers

Some parts of used products recycled by distributors with less damage degree can be used directly in the process of maintenance. The process can achieve an obvious quality of economy and environment protection of the parts.

(6) Using entities and individuals

As the end of the forward logistics, the using entities as well as individuals hold and maintain the products with the longest time. They ought to return the products to distributors or OEM for remanufacturing in the optimal timing with compensation, which is an efficient approach to achieve obvious quality of economy and environment protection.

The recycling mode is composed of three layers: Manufacturing and Remanufacturing Layer, Middle Layer and User Layer. OEM is the core of the recycling operation mode, mechanical and distributor is a key role in recycling process. The sale-buyback contract should be signed by OEM, distributors and users when purchasing behaviors occur. Users should return products to OEM or distributors in the optimal timing for active remanufacturing. Then distributors send them back to OEM for remanufacturing and return the better parts to maintainers for maintenance. The remanufacturing department of OEM shall be responsible for the remanufacturing of waste products. OEM should entrust a third-party remanufacturers for remanufacturing when it does not have remanufacturing department or the quantity of waste products is significant. The parts manufactured by upstream parts suppliers need to be returned to parts suppliers for remanufacturing. Remanufacturing products will be returned to users or maintainers for maintenance.

In conclusion, only with the joint efforts of three layers can this mode play the extreme positive role and can products achieve the benefits of economy and environment protection.

\section{Example applications}

Engine is a kind of commonly used electro-mechanical equipment, and the connecting rod is the one of the core components in engine. To validate the optimal timing model and obtain the economic benefits of the recovery mode for products' active remanufacturing, a certain type of connecting rod is taken as a case study.

In the present study, 50 samples of waste connecting rods are selected, and the statistical analysis results show that,

(1) Connecting rod serving time obeys normal distribution, $N\left(4.4,1.39^{2}\right)$;

(2) Uncertainty of damage degree of connecting rods: mild grind occupies $86.36 \%$, the percent of severe grind is $13.64 \%$;

(3) Uncertainty of process: through the research, for wear and tear of the connecting rods, the probability distributions of the energy consumption of coarsening, spraying, fine grinding and polishing and the quantity of spraying with iron are triangular distribution.

Based on the model presented above, each sample is calculated with Monte Carlo simulation method for $10^{5}$ times. Then, the annual average costs of environmenteconomy under different service time can be obtained. According to the service time and annual average costs of environment-economy, the annual average total affect curve equation can be obtained using the least square method. The curve equation is,

$$
y=0.292 t^{2}-2.898 t+1343.357
$$

The annual average total affect curve of connecting rod is shown in Figure 7. The numerical statistics of $10^{5}$ lowest points is shown in Figure 8.

Under the confidence interval of $95 \%$, the optimal timing

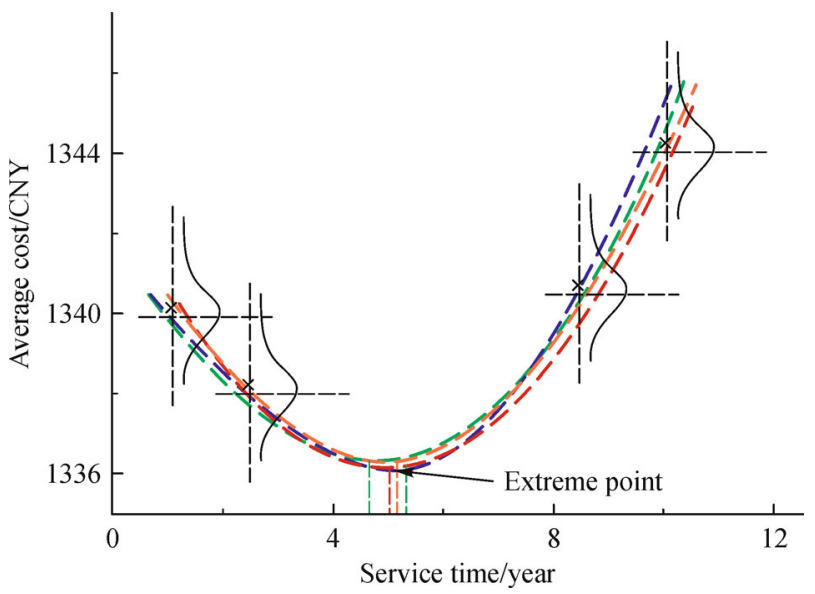

Figure 7. The annual average cost of environment-economy of connecting rod. 


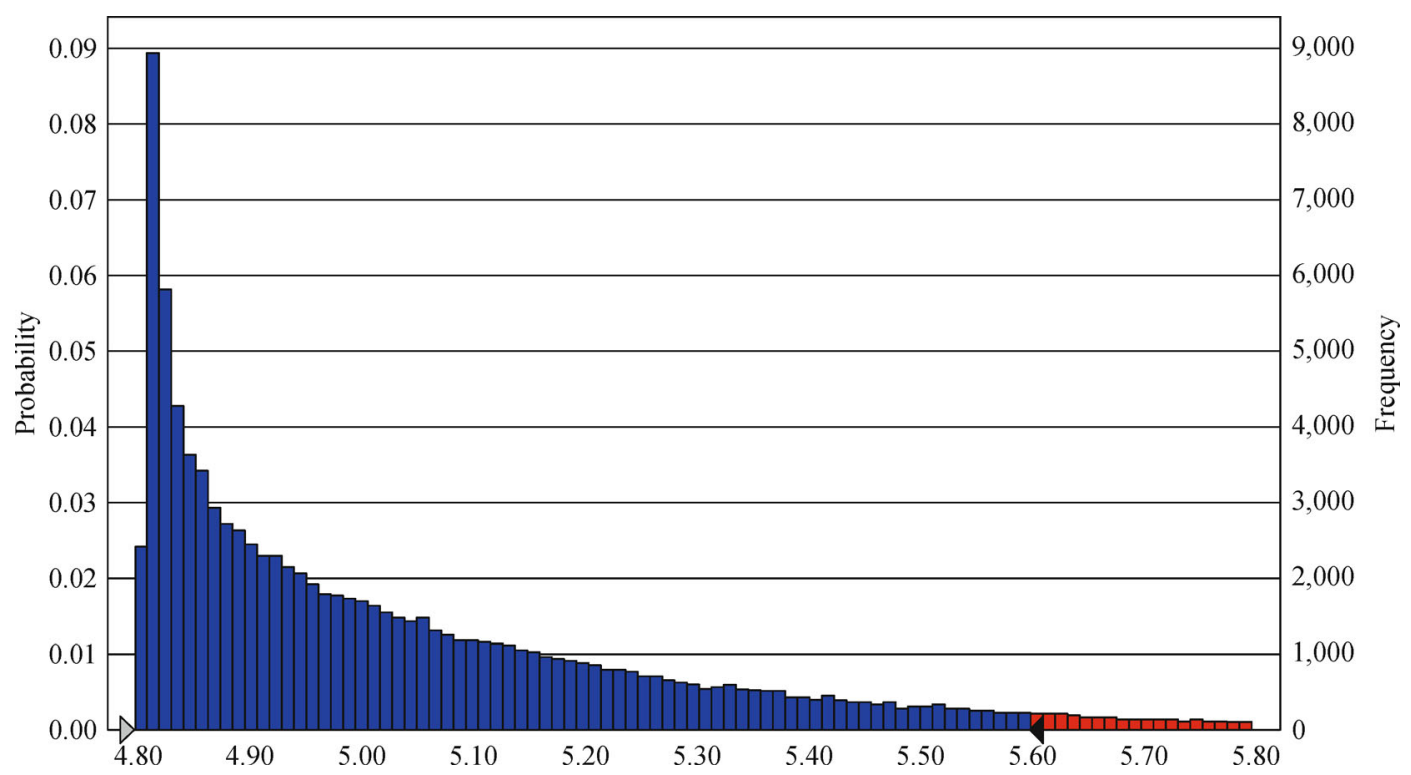

Figure 8. The optimal timing interval for active remanufacturing.

for active remanufacturing of connecting rod is $\frac{-\hat{\beta}_{2}}{2 \hat{\beta}_{1}} \in(4.8,5.6)$. Therefore, the optimal timing for active remanufacturing of connecting rod is $4.8 \sim 5.6$ years.

Under the confidence interval of $95 \%$, the saving money of each connecting rod is from 2.36 to $2.75 \mathrm{CNY}$. Each connecting rod saves $2.53 \mathrm{CNY}$ on average, six connecting rods save $15.18 \mathrm{CNY}$ altogether in an engine.

\section{Conclusions}

(1) Through the failure analysis of the product's whole life cycle, this paper proposed the optimal timing model for active remanufacturing of electro-mechanical products based on LCA and LCC. This model can achieve the biggest use value of products' mechanical properties and minimize the input for remanufacturing. And the economic benefits and environmental protection can be achieved.

(2) Based on the optimal timing model, a product recycling operation mode is proposed. According to this mode, products remanufactured in the optimal timing are more favorable than traditional end-of-life remanufacturing in terms of costs and environment.

Acknowledgements This research was supported by grants from the National Basic Research Program of China (2011CB013406).

\section{References}

Bose, I., \& Anand, P. (2007). On returns policies with exogenous price. European Journal of Operational Research, 178, 782-788.

Bras, B., \& Hammond, R. (1996). Towards design for remanufacturing- metrics for assessing remanufacturability. Proceedings of the $1 s t$ International Workshop on Reuse, 5-22.

Fleischmann, M., Beullens, P., Bloemhof-Ruwaard, J. M., \& Van Wassenhove, L. N. (2001). The impact of product recovery on logistics network design. Production and Operations Management, 10, 156-173.

Fleischmann, M., Van Nunen, J., \& Gräve, B. (2003). Integrating closedloop supply chains and spare-parts management at IBM. Interfaces, $33,44-56$.

Frank, C., \& Yakut, E. (2004). Process design to mobiles in the remanufacturing network. In Proceedings Global Conference on Sustainable Product Development and Life Cycle Engineering, 191198.

Galbreth, M., \& Blackburn, J. (2010). Optimal acquisition quantities in remanufacturing with condition uncertainty. Production and Operations Management, 19, 61-69.

Guide, V. Jr. (2000). Production planning and control for remanufacturing: industry practice and research needs. Journal of Operations Management, 18, 467-483.

Guide, V., \& Van Wassenhove, L. (2002). The reverse supply chain. Harvard Business Review, 02.

Guide, V. Jr, \& Van Wassenhove, L. (2009). The evolution of closed-loop supply chain research. Operations Research, 57, 10-18.

Hellweg, S., \& Canals, L. (2014). Emerging approaches, challenges and opportunities in life cycle assessment. Science, 344, 1109-1113.

Herbes, C., Friege, C., Baldo, D., \& Mueller, K. (2015). Willingness to pay lip service? Applying a neuroscience-based method to WTP for green electricity. Energy Policy, 87, 562-572.

Huang, X. (1990). Reliability engineering. Beijing: Tsinghua University Press.

Ketzenberg, M. E., van der Laan, E., \& Teunter, R. H. (2006). Value of information in closed loop supply chains. Production and Operations Management, 15, 393-406.

Liu, C., Cao, H., Liu, F., Du, Y., \& Ding, C. (2007). Comprehensive 
assessment model and its application of waste electromechanical products green remanufacturing. Modern Manufacturing Engineering, 11, 1-4.

Liu, G., Liu, T., Ke, Q., Song, S., \& Zhou, D. (2013). Time interval decision-making method for active remanufacturing product based on Game Theory and Neural Network. Journal of Mechanical Engineering, 49, 29-35.

Liu, Y., Xu, B., Shi, P., \& Liu, B. (2011). Assessment indexes of used products remanufacturability. China Surface Engineering, 24, 94-99.

Liu, Z., Jiang, Q., Li, T., \& Zhang, H. (2014). An optimal timing of engine remanufacturing-a real option approach. In 21st CIRP Conference on Life Cycle Engineering, Procedia CIRP. 15, 223-227.

Mckenna, R., Reith, S., Cail, S., Kessler, A., \& Fichtner, W. (2013). Energy savings through direct secondary reuse: an exemplary analysis of the German automotive sector. Journal of Cleaner Production, 52, $103-112$

Örsdemir, A., Kemahlıglu-Ziya, E., \& Parlaktürk, A. (2014). Competitive quality choice and remanufacturing. Production and Operations Management, 23, 48-64.

Pasternack, B. (1985). Optimal pricing and returns policies for perishable commodities. Marketing Science, 4, 166-176.

Seliger, G., Frank, C., Ciupek, M., \& Basdere, B. (2004). Process and facility planning for mobile phone remanufacturing. Annals of the CIRP, 53, 9-12.

Stock, J. (1992). Reverse logistics. Illinois: Council of Logistics Management, Oak Brook.
Teunter, R., \& Flapper, S. (2010). Optimal core acquisition and remanufacturing policies under uncertain core quality fractions. European Journal of Operational Research, 210, 241-248.

$\mathrm{Xu}$, B. (2007). Theory and technology of equipment remanufacture engineering. Beijing: National Defense Industry Press.

$\mathrm{Xu}, \mathrm{B}$. (2010). State of the art and future development in remanufacturing engineering. Transactions of Materials and Heat Treatment, 31, 1014.

Xu, B., Dong, S., \& Shi, P. (2013). States and prospects of China characterized quality guarantee technology system for remanufactured parts. Journal of Mechanical Engineering, 49, 84-90.

Zalejska-Jonsson, A. (2014). Stated WTP and rational WTP: Willingness to pay for green apartments in Sweden. Sustainable Cities and Society, 13, 46-56.

Zhang, J., \& Chen, M. (2015). Assessing the impact of China's vehicle emission standards on diesel engine remanufacturing. Journal of Cleaner Production, 107, 177-184.

Zhong, J., Fan, S., Yao, Y., \& Yang, Y. (2003). Research on synthetical assessment for remanufacturability. Zhongguo Jixie Gongcheng, 14, $2110-2113$

Zhu, S., Xu, B., \& Yao, J. (2003). Study of the foundation and method of remanufacturing design. China Surface Engineering, 16, 27-31.

Zikopoulos, C., \& Tagaras, G. (2007). Impact of uncertainty in the quality of returns on the profitability of asingle-period refurbishing operation. European Journal of Operational Research, 182, 205225 . 